Check for updates

Cite this: Chem. Sci., 2019, 10, 8411

๑ All publication charges for this article have been paid for by the Royal Society of Chemistry

Received 15th May 2019

Accepted 9th July 2019

DOI: $10.1039 / c 9 s c 02372 k$

rsc.li/chemical-science

\section{Oxidant speciation and anionic ligand effects in the gold-catalyzed oxidative coupling of arenes and alkynes $\uparrow$}

\author{
Manuel Hofer, ${ }^{a}$ Teresa de Haro, ${ }^{a}$ Enrique Gómez-Bengoa, (D) ${ }^{\mathrm{b}}$ Alexandre Genoux ${ }^{\mathrm{a}}$ \\ and Cristina Nevado (D) *a
}

\begin{abstract}
The mechanism of the gold-catalyzed oxidative cross-coupling of arenes and alkynes has been studied in detail combining stoichiometric experiments with putative reaction intermediates and DFT calculations. Our data suggest that ligand exchange between the alkyne, the Au(I)-catalyst and the hypervalent iodine reagent is responsible for the formation of both an $A u(1)$-acetylide complex and a more reactive "nonsymmetric" I(III) oxidant responsible for the crucial Au(I)/Au(II) turnover. Further, the reactivity of the in situ generated $\mathrm{Au}(\mathrm{III})$-acetylide complex is governed by the nature of the anionic ligands transferred by the I(III) oxidant: while halogen ligands remain unreactive, acetato ligands are efficiently displaced by the arene to yield the observed $\mathrm{Csp}^{2}-\mathrm{Csp}$ cross-coupling products through an irreversible reductive elimination step. Finally, the nature of competitive processes and catalyst deactivation pathways has also been unraveled. This detailed investigation provides insights not only on the specific features of the species involved in oxidative gold-catalyzed cross couplings but also highlights the importance of both ancillary and anionic ligands in the reactivity of the key $\mathrm{Au}(\mathrm{II})$ intermediates.
\end{abstract}

\section{Introduction}

Aryl alkynes have found widespread use as building blocks in the synthesis of numerous natural products, bioactive molecules and organic materials. ${ }^{1}$ In recent years, metal-catalyzed $\mathrm{Csp}^{2}-\mathrm{H}$ bond functionalizations have been explored as an alternative strategy to classical Pd-catalyzed cross-coupling reactions for the efficient construction of $\mathrm{Csp}^{2}$-Csp bonds. ${ }^{2}$ These approaches are attractive because they avoid the otherwise necessary pre-functionalization of the aromatic partner. However, and in contrast to the large body of metal-catalyzed $\mathrm{Csp}^{2}-\mathrm{H}$ arylation reactions, ${ }^{3}$ the direct $\mathrm{Csp}^{2}-\mathrm{H}$ alkynylation of arenes has been much less explored. Few examples though have shown the viability of this strategy. ${ }^{4}$ In 2010 , the Cu-catalyzed direct alkynylation of electron deficient polyfluoroarenes with terminal alkynes using $\mathrm{O}_{2}$ as the oxidant was reported by $\mathrm{Su}$ et al. ${ }^{5}$ Despite its efficiency, the reaction is barely catalytic and relies on the acidity of the $\mathrm{Csp}^{2}-\mathrm{H}$ bond in the arene substrate. A different approach focused on the stoichiometric use of alkynyliodonium species as an electrophilic source of acetylenic

${ }^{a}$ Department of Chemistry, University of Zürich, Winterthurerstrasse 190, Zürich, CH-8057, Switzerland. E-mail: cristina.nevado@chem.uzh.ch

${ }^{b}$ Departamento de Quimica Orgánica I, Universidad del Pais Vasco, Apdo 1072, CP20080 Donostia-San Sebastián, Spain

$\dagger$ Electronic supplementary information (ESI) available. CCDC 1008765. For ESI and crystallographic data in CIF or other electronic format see DOI: $10.1039 / \mathrm{c} 9 \mathrm{sc} 02372 \mathrm{k}$ moieties in the presence of catalytic amounts of late transition metals as demonstrated by Waser et al. ${ }^{6}$ In this context, our group reported an oxidative alkynylation of arenes via Au-catalyzed $\mathrm{C}-\mathrm{H}$ functionalization of both Csp- and $\mathrm{Csp}^{2}-\mathrm{H}$ bonds (eqn (1) and Scheme 1). ${ }^{7}$ One of the most remarkable features of this protocol was the use of "deactivated" electron rich arenes and electron deficient alkynes as coupling partners. A catalytic amount of $\mathrm{Ph}_{3} \mathrm{PAuCl}$ in combination with commercially available $\mathrm{PhI}(\mathrm{OAc})_{2}$ as the stoichiometric oxidant was found to be effective in producing new $\mathrm{Csp}^{2}$-Csp bonds. ${ }^{8} \mathrm{~A}$ stoichiometric version of this transformation had been already described by Fuchita and co-workers back in 2001. ${ }^{9}$

In the catalytic version, a hypervalent iodine reagent ${ }^{10}$ was selected as the oxidant on the basis of significant evidence that these species could promote $\operatorname{Pd}(\mathrm{II}) / \mathrm{Pd}(\mathrm{Iv})$ catalytic cycles. ${ }^{11} \mathrm{We}$

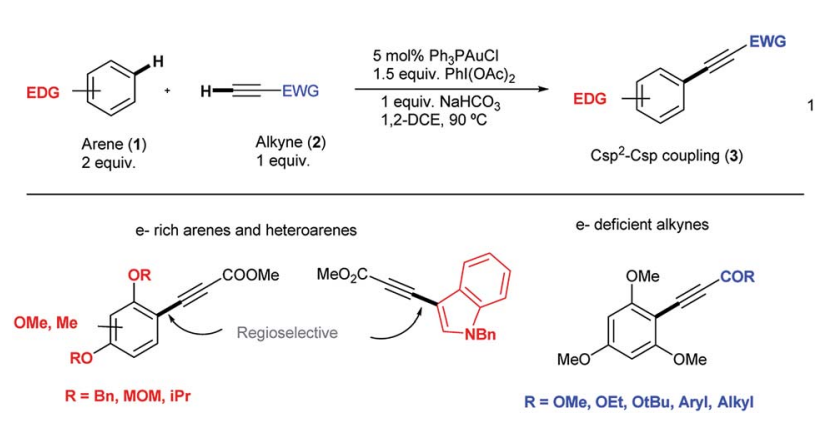

Scheme 1 Au-catalyzed alkynylation of arenes. 
thus anticipated that a $\mathrm{Au}(\mathrm{I}) / \mathrm{Au}(\mathrm{III})$ catalytic turnover could be implemented under the reaction conditions. Furthermore, the ability of $\mathrm{Au}$ (III) species to trigger $\mathrm{Csp}^{2}-\mathrm{H}$ activation in electron rich arenes is also well established. ${ }^{9,12}$ Although $\mathrm{Au}(\mathrm{I}) / \mathrm{Au}(\mathrm{III})$-catalyzed reactions have recently emerged as powerful tools for $\mathrm{C}-\mathrm{C}$ cross couplings, ${ }^{13}$ with few notable exceptions, ${ }^{14}$ the mechanistic understanding of these processes is still limited and the characterization of putative intermediates is scarce. We report herein a detailed investigation aiming to elucidate the factors governing both reactivity and selectivity in these transformations.

In our previous work, ${ }^{7}$ the mechanistic rationale involved: (i) an equilibrium between the free alkyne and the Au catalyst with the aid of a base to form a Au(I)-acetylide complex (I); (ii) oxidation of I with $\mathrm{PhI}(\mathrm{OAc})_{2}$ to form $\mathrm{Au}(\mathrm{III})$ species II; (iii) arene auration to produce intermediate III which evolves via reductive elimination (iv) yielding product IV (Scheme 2, path A.1). Alternatively, in line with Waser's reports on the stoichiometric use of alkynyliodonium salts, ${ }^{6}$ a ligand exchange between $\mathrm{PhI}(\mathrm{OAc})_{2}$ and $\mathrm{Au}(\mathrm{I})$-acetylide (I) to give an alkynyliodonium intermediate (V) could also be proposed. Arene addition to give VI followed by $\beta$-Au elimination would then furnish product IV as shown in path B.1 of Scheme 2 . Alternatively, transmetalation between alkynyliodonium salt $\mathbf{V}$ and putative aryl-Au(III) species (VII) produced in situ within the oxidative reaction media $^{\mathbf{1 2}}$ could also deliver intermediate III, which would yield the observed products after reductive elimination as shown in Scheme 2, path B.2.

Our preliminary study left open several key questions: first and foremost, the role of $\mathrm{PhI}(\mathrm{OAc})_{2}$ needed to be established, whether it functioned as a stoichiometric oxidant to achieve the $\mathrm{Au}(\mathrm{I}) / \mathrm{Au}$ (III) turnover or as an electrophilic source to exchange and then cross-couple the alkyne to an electron rich arene, or both. In addition, the order of steps needed to be clarified as to whether the transfer of the alkyne to the gold(I) complex (path A.1) or a direct oxidation (path A.2) was involved in the initial step of the catalytic cycle. Furthermore, neither detailed information about the metal coordination sphere in the proposed $\mathrm{Au}(\mathrm{III})$ intermediates II and III nor about the oxidant environment was available from these initial investigations. ${ }^{7}$

\section{Results and discussion}

Initial experiments ${ }^{\mathbf{1 5}}$ to investigate the feasibility of pathways B.1 and B.2 focused on alkynyliodonium salts (V) in order to reveal their potential role as intermediates in these transformations.

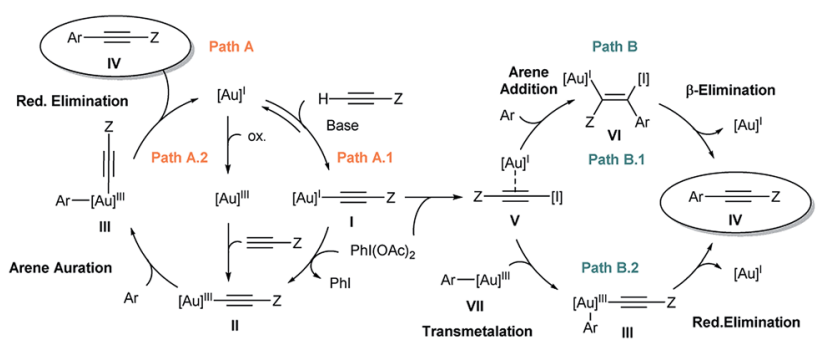

Scheme 2 Plausible mechanisms for Au-catalyzed alkynylation of arenes.

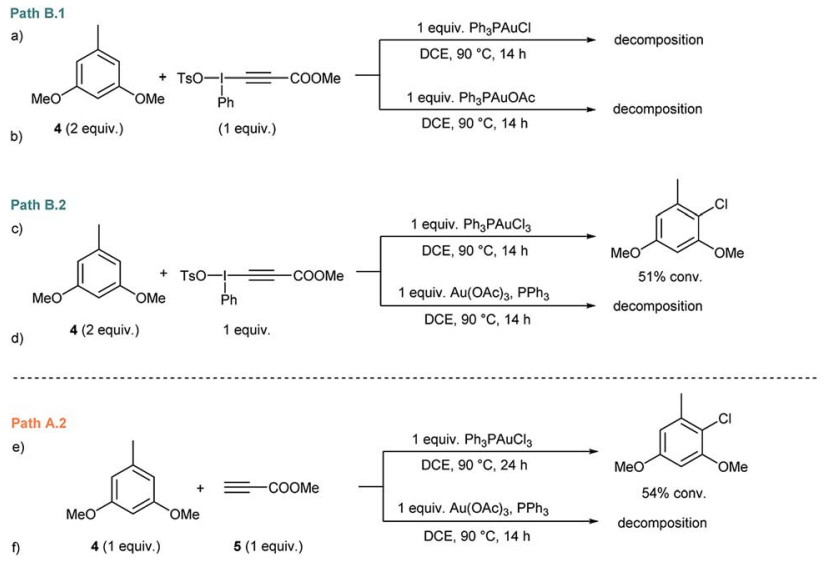

Fig. $1(a-d)$ Stoichiometric experiments involving alkynyliodonium species (paths B.1 and B.2 in Scheme 2). (e and f) Stoichiometric experiments regarding path A.2.

Treatment of methyl 3-(phenyl(tosyloxy)- $\lambda^{3}$-iodanyl)propiolate with stoichiometric amounts of 3,5-dimethoxytoluene (4) and $\mathrm{Ph}_{3} \mathrm{PAuCl}$ or $\mathrm{Ph}_{3} \mathrm{PAuOAc}$ at $90{ }^{\circ} \mathrm{C}$ did not furnish the desired $\mathrm{Csp}^{2}$-Csp cross coupling product and only decomposition of the alkynyliodonium salt was detected (Fig. 1a and b). Identical experiments in the presence of gold(III) complexes like $\mathrm{Ph}_{3} \mathrm{PAuCl}_{3}$ or $\mathrm{Au}(\mathrm{OAc})_{3} / \mathrm{PPh}_{3}$ showed a similar outcome (Fig. 1c and d). Interestingly, in the case of $\mathrm{Ph}_{3} \mathrm{PAuCl}_{3}$ formation of 2-chloro-1,5dimethoxy-3-methylbenzene as the by-product could be observed. ${ }^{12 a}$ These control experiments (Section 2 in the ESI $\dagger$ ) led us to rule out pathways B.1 and B.2 and the participation of alkynyliodonium species $\mathbf{V}$ as intermediates in these transformations.

Experiments to investigate pathway A.2 involved the participation of the alkyne in the presence of gold(III) species. However, stoichiometric experiments with 3,5-dimethoxytoluene (4), methyl propiolate (5) and $\mathrm{Ph}_{3} \mathrm{PAuCl}_{3}$ or $\mathrm{Au}(\mathrm{OAc})_{3} / \mathrm{PPh}_{3}$ at $90{ }^{\circ} \mathrm{C}$ showed the formation of the arylchloride in the case of $\mathrm{Ph}_{3} \mathrm{PAuCl}_{3}$ but no participation of the alkyne (Fig. 1e and f). To explore the direct oxidation of the initial catalyst, $\mathrm{Ph}_{3} \mathrm{PAuCl}$ was treated with an excess of $\mathrm{PhI}(\mathrm{OAc})_{2}$ at $90{ }^{\circ} \mathrm{C}$. However, no reaction was observed even after prolonged heating and just $\mathrm{Ph}_{3} \mathrm{PO}$ could be detected in trace amounts (Fig. S2 and S3 in the ESI $\dagger$ ). These experiments suggest that the neutral $\mathrm{Ph}_{3} \mathrm{PAuCl}$ complex used as the catalyst is scarcely oxidized by $\mathrm{PhI}(\mathrm{OAc})_{2}$ under the reaction conditions, in contrast to previous results obtained for $\mathrm{PhICl}_{2}$ which furnished $\mathrm{Ph}_{3} \mathrm{PAuCl}_{3}$ in $96 \%$ yield even at room temperature. ${ }^{16}$ In situ oxidation of the $\mathrm{Au}$ (I) catalyst also seems to be at the outset of the Au-catalyzed oxidative oxo- and aminoarylation of alkenes with boronic acids. ${ }^{14 a, b}$ However, the results described herein clearly indicate that the present alkynylation reaction proceeds, at least at the outset, through an alternative reaction mechanism.

\section{Formation and reactivity of $\mathrm{Au}(\mathrm{I})$-acetylide (8)}

To investigate path A.1, a careful spectroscopic analysis $\left({ }^{1} \mathrm{H}\right.$ and $\left.{ }^{31} \mathrm{P} \mathrm{NMR}\right)$ of the reaction mixture stemming from the reaction between 3,5-dimethoxytoluene (4) and methyl propiolate (5) under the standard conditions ( $5 \mathrm{~mol} \% \mathrm{Ph}_{3} \mathrm{PAuCl}, 1.5$ equiv. $\mathrm{PhI}(\mathrm{OAc})_{2}$, 1 equiv. $\mathrm{NaHCO}_{3}$ ) was performed. The reaction showed the 
presence of three species: the initial catalyst $\mathrm{Ph}_{3} \mathrm{PAuCl}$, $\left[\left(\mathrm{Ph}_{3} \mathrm{P}\right)_{2} \mathrm{Au}\right] \mathrm{Cl}(7)$ and a $\mathrm{Ph}_{3} \mathrm{PAu}\left(\mathrm{C} \equiv \mathrm{C}-\mathrm{CO}_{2} \mathrm{Me}\right)$ complex (8) (Fig. 2a, S4 and S5 in the ESI $\dagger$ ).

Complex 8 appears already after the first minutes of the reaction and it disappears towards the end whereas $\mathrm{Ph}_{3} \mathrm{PAuCl}$ and 7 are present after the starting materials have been completely consumed. $\mathrm{Ph}_{3} \mathrm{PO}$ could not be detected in the reaction mixture. These results indicate that the phosphine ligand remains bound to the metal center and thus does not get oxidized by $\mathrm{PhI}(\mathrm{OAc})_{2}$ in appreciable quantities. In situ generated phosphine-free $\mathrm{Au}(\mathrm{III})$ species have been proved to be the productive intermediates in the recently reported Au-catalyzed cross coupling reaction of aryl silanes with arenes. ${ }^{\mathbf{1 4 c}}$ Interestingly, a catalytic reaction in the presence of IPrAuCl gave no product conversion, thus highlighting the importance of the ancillary ligand in these transformations.

Once the species detected during the reaction had been identified, we decided to interrogate in detail both the mechanism for the formation, as well as the reactivity of the $\mathrm{Au}(\mathrm{I})$ acetylide complex $\mathbf{8}$. We monitored the formation of $\mathbf{8}$ from $\mathrm{Ph}_{3} \mathrm{PAuCl}$, methyl propiolate (5) and $\mathrm{NaHCO}_{3}$ by both ${ }^{1} \mathrm{H}$ and ${ }^{31} \mathrm{P}$ NMR performing the reaction in $\mathrm{CD}_{2} \mathrm{Cl}_{2}$. Experimentally, the formation of complex $\mathbf{8}$ is not a favorable process, and even after prolonged heating, it could only be detected in marginal amounts (Fig. 2b, S6 and S7 in the ESI $\dagger$ ). In contrast, the same reaction in the presence of $\mathrm{PhI}(\mathrm{OAc})_{2}$ revealed the presence of 8 after only 5 minutes (Fig. 2c, S8 and S9 in the ESI $\dagger$ ), in line with the spectroscopic analysis of a catalytic reaction (Fig. 2a). Interestingly, the reaction of $\mathrm{Ph}_{3}$ PAuOAc with 5 proceeded quantitatively at room temperature in the absence of oxidant producing 8 and $\mathrm{AcOH}$ in only 10 minutes (Fig. 2d). On the other hand, the reverse reaction, although not unfeasible, is not a favorable process. These observations suggested an additional
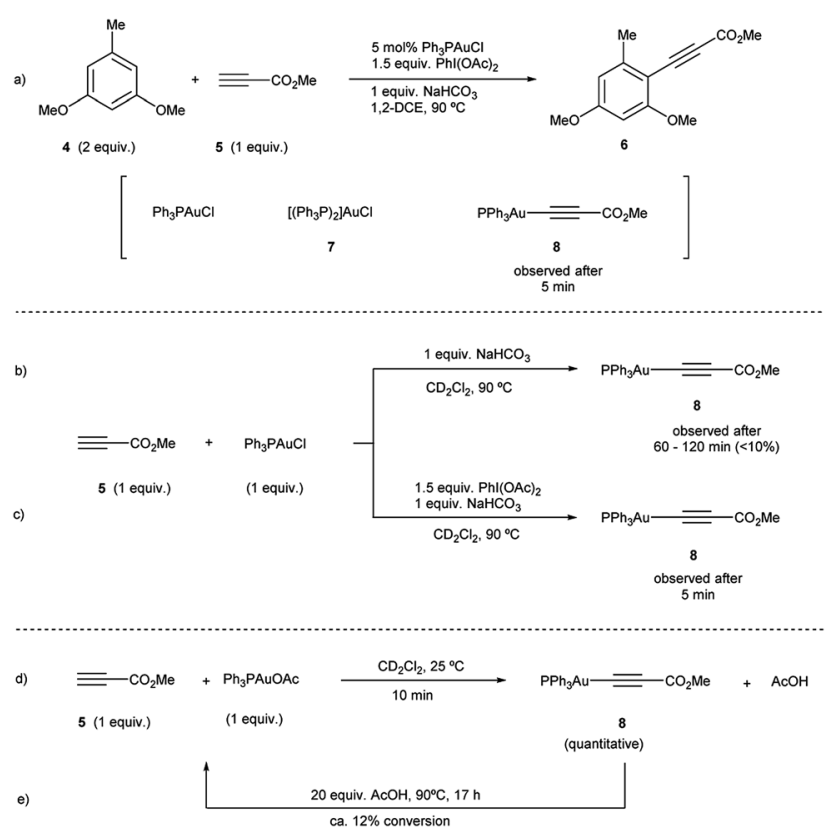

Fig. 2 (a) Standard catalytic reaction. (b and c) Experiments towards the formation of $\mathrm{Au}(\mathrm{l})$-acetylide 8 from $\mathrm{Ph}_{3} \mathrm{PAuCl}$ and alkyne 5 in the absence or presence of Phl(OAc) 2 , respectively. ( $d$ and e) Reactivity of $\mathrm{Ph}_{3} \mathrm{PAuOAc}$ towards methyl propiolate (5). and unexpected new role of the oxidant in the initial steps of the reaction: $\mathrm{PhI}(\mathrm{OAc})_{2}$ favors the formation of the observed complex 8 (Fig. S10-S13 in the ESI $\dagger$ ).

The reactivity of the $\mathrm{Au}(\mathrm{I})$-acetylide $\mathbf{8}$ was studied next. Gold acetylides have been proposed as productive reaction intermediates in different transformations including the formation of $\mathrm{Au}$ vinylidenes ${ }^{\mathbf{1 7}}$ or the Au-catalyzed homo- ${ }^{\mathbf{1 8}}$ and heterocoupling ${ }^{19}$ of alkynes. The reaction of 8 with $\mathrm{PhI}(\mathrm{OAc})_{2}$ in $\mathrm{CD}_{2} \mathrm{Cl}_{2}$ was monitored by ${ }^{1} \mathrm{H}$ and ${ }^{31} \mathrm{P}$ NMR. Indeed, no conversion was observed up to $60{ }^{\circ} \mathrm{C}$ while only very low conversion into $\mathrm{Ph}_{3} \mathrm{PAuOAc}$ and $\mathrm{Ph}_{3} \mathrm{PAuCl}$ was detected even after prolonged heating at $90{ }^{\circ} \mathrm{C}$ (eqn (2), Fig. S14 and S15 in the ESI $\dagger){ }^{20}$ These results indicate that 8 is hardly oxidized with $\mathrm{PhI}(\mathrm{OAc})_{2}$ and also that the putative oxidation product $\mathrm{Ph}_{3} \mathrm{PAu}\left(\mathrm{C} \equiv \mathrm{C}-\mathrm{CO}_{2} \mathrm{Me}\right)(\mathrm{OAc})_{2} 9$ is rather unstable under the reaction conditions undergoing rapid reductive elimination to give $\mathrm{Ph}_{3} \mathrm{PAuOAc}$ and 3-(acetyloxy)-methyl propiolate (which decomposes in situ due to its highly labile nature).

In sharp contrast, the reaction of $\mathbf{8}$ in the presence of $\mathrm{PhICl}_{2}$ cleanly proceeded at room temperature to give cis-Ph ${ }_{3} \mathrm{PAu}\left(\mathrm{C} \equiv \mathrm{C}-\mathrm{CO}_{2} \mathrm{Me}\right)(\mathrm{Cl})_{2}$ keep "cis-Ph3PAu(CC-CO2Me)(Cl)2 (10)" in single line(10), whose structure could be confirmed by $\mathrm{X}$-ray diffraction analysis (eqn (3)). These results not only showcase the different oxidizing abilities of $\mathrm{PhI}(\mathrm{OAc})_{2}$ vs. $\mathrm{PhICl}_{2}$ but also the influence of the ligand transferred by the hypervalent iodine reagent on the stability of the corresponding $\mathrm{Au}(\mathrm{III})$ intermediates produced in the reaction mixture. When 8 and $\mathrm{PhICl}_{2}$ were stirred at higher temperature, reductive elimination on $\mathbf{1 0}$ occurred, furnishing $\mathrm{Ph}_{3} \mathrm{PAuCl}$, which is oxidized in the presence of the remaining oxidant to $\mathrm{Ph}_{3} \mathrm{PAuCl}_{3}$. In this case, the by-product stemming from reductive elimination (i.e. 3-chloro-methyl propiolate $\mathbf{1 1}^{\mathbf{2 1}}$ ) could be clearly observed (eqn (4), Fig. S20 and S21 in the ESI $\dagger$ ).

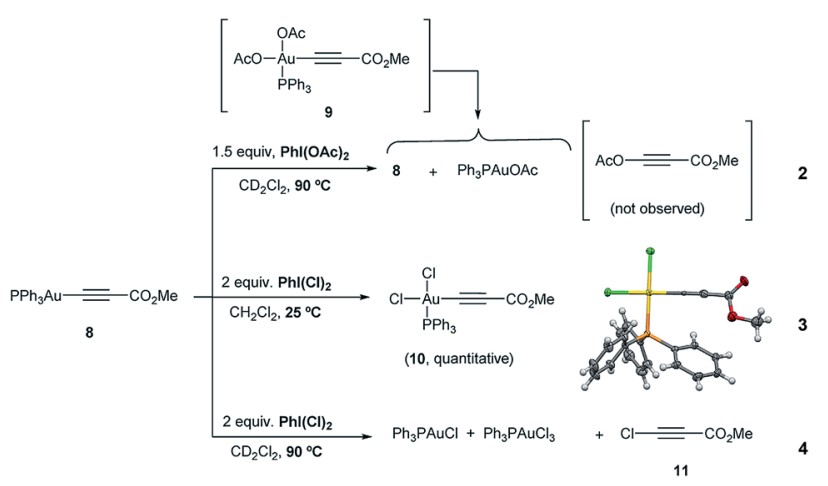

Due to the labile nature of complex 9, we decided to seek an alternative model system to study the reactivity of the putative $\mathrm{Au}(\mathrm{III})$ intermediates produced during the aryl alkynylation reaction. $\mathrm{Ph}_{3} \mathrm{PAuC}_{6} \mathrm{~F}_{5}$ (12) was selected expecting that the electron deficient nature of the pentafluorophenyl ligand could mimic that of the propiolate unit while offering a more stable platform for the isolation of gold(III) species. Reaction of $\mathrm{Ph}_{3} \mathrm{PAuC}_{6} \mathrm{~F}_{5}$ (12) with $\mathrm{PhI}(\mathrm{OAc})_{2}$ in a 1:1 mixture of hexafluorobenzene/benzene at $80{ }^{\circ} \mathrm{C}$ delivered trans- $\mathrm{Ph}_{3} \mathrm{PAu}\left(\mathrm{C}_{6} \mathrm{~F}_{5}\right)(\mathrm{OAc})_{2}$ (13) in $64 \%$ yield according to our previously reported procedure (eqn (5)). ${ }^{22}$ 
<smiles>Fc1c(F)c(F)c(N=Cc2ccccc2)c(F)c1F</smiles>

12

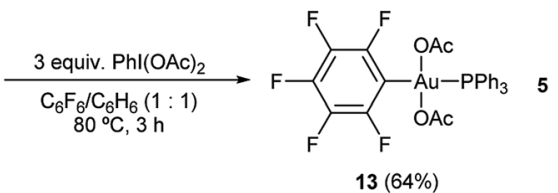

$13(64 \%)$

\section{Reactivity of putative Au(III)-intermediates}

We set out to examine the reactivity of complexes $\mathbf{1 0}$ and $\mathbf{1 3}$ towards the species present in the media during the standard aryl alkynylation reaction, namely: methyl propiolate (5), Au(I)acetylide complex (8) and electron-rich arenes in a stoichiometric fashion. The results of this study have been summarized in Table 1. Interestingly, trans $-\mathrm{Ph}_{3} \mathrm{PAu}\left(\mathrm{C}_{6} \mathrm{~F}_{5}\right)(\mathrm{OAc})_{2}(\mathbf{1 3})$ reacted with methyl propiolate (5) at $25{ }^{\circ} \mathrm{C}$ to give methyl 3-(pentafluorophenyl)-prop-2-ynoate (14) in $68 \%$ yield together with $\mathrm{Au}(\mathrm{I})$-acetylide complex $\mathbf{8}$ as a result of the double replacement of both acetato ligands with free alkyne followed by reductive elimination (see Fig. S22 and S23 in the ESI $†$ ). The reaction of $\mathbf{1 3}$ with complex 8 was also illustrative, providing 14 in $62 \%$ yield together with $\mathrm{Ph}_{3} \mathrm{PAuOAc}$. Since no $\mathrm{Au}(\mathrm{I})$-acetylide complex 8 was detected at the end of the reaction, we have to assume that upon a first $\mathrm{Au}(\mathrm{I}) / \mathrm{Au}(\mathrm{III})$ transmetalation (which could also be described as a $\mathrm{Au}(\mathrm{I}) / \mathrm{Au}(\mathrm{III})$ ligand exchange reaction), $\mathrm{Csp}^{2}$-Csp reductive elimination occurs fast, preventing a second ligand transfer between the different gold species (see Fig. S24 and S25 in the ESI†). Finally, the reactions of $\mathbf{1 3}$ with 1,3,5-trimethoxybenzene, 1,3-dimethoxytoluene 4 and $N$-methyl indole were also enlightening as they proceeded efficiently towards the corresponding cross-coupling products $\mathbf{1 5}, \mathbf{1 6}$ and $\mathbf{1 7}$ in 85, 74 and $85 \%$ yield, respectively. ${ }^{16 b, 23}$

Table 1 Comparison of reactivity between Au(III)-bis-chloro vs. bisacetato complexes

\begin{tabular}{|c|c|c|}
\hline $\begin{array}{l}\text { Reactivity } \\
\text { OAC vs. CI }\end{array}$ & $\begin{array}{c}\mathrm{OAc} \\
\mathrm{C}_{6} \mathrm{~F}_{5}-\mathrm{Au}_{\mathrm{Pu}-\mathrm{PPh}_{3}} \\
\mathrm{OAAc} \\
\mathbf{1 3}\end{array}$ & $\begin{array}{c}\mathrm{Cl} \\
\mathrm{Cl}-\mathrm{Au}_{\substack{\mathrm{l} \\
\mathrm{PPh}_{3}}}=\text { COOMe } \\
10\end{array}$ \\
\hline $\bar{F}_{5} \mathrm{CO}_{2} \mathrm{Me}$ & $\mathrm{C}_{6} \mathrm{~F}_{5}=\mathrm{CO}_{2} \mathrm{Me}$ & No Reaction ${ }^{d}$ \\
\hline $\mathrm{Ph}_{3} \mathrm{PAu}=\frac{\overline{8}}{\overline{8}} \mathrm{CO}_{2} \mathrm{Me}$ & $\begin{array}{c}\mathrm{C}_{6} \mathrm{~F}_{5}=\mathrm{CO}_{2} \mathrm{Me} \\
14(62 \%)^{b}\end{array}$ & $\mathrm{MeO}_{2} \mathrm{C}=\underset{18 \text { (quant.) }}{=} \mathrm{CO}_{2} \mathrm{Me}^{\mathrm{e}}$ \\
\hline $\int_{4}^{\mathrm{Me}}$ & (85\%) & No reaction ${ }^{f}$ \\
\hline
\end{tabular}

${ }^{a} \mathrm{Au}\left(\mathrm{I}\right.$ )-acetylide 8 was also detected. ${ }^{b} \mathrm{Ph}_{3}$ PAuOAc was also detected. ${ }^{c}$ Compound 16 is obtained as a $0.6: 1$ mixture of regioisomers.

${ }^{d}$ Traces of alkyne homocoupling product 18 were detected.

${ }^{e} \mathrm{Ph}_{3} \mathrm{PAuCl}$ was also detected. ${ }^{f}$ See also ref. $16 b$.

The reactivity pattern observed for cis-dichloro(methoxycarbonylethynyl) (triphenylphosphine)-gold(III) (10) turned out to be completely different as shown on the right column of Table 1. In contrast to 13, complex 10 did not react with methyl propiolate (5) (Fig. S26 and S27 in the ESI†) although it underwent transmetalation with $\mathrm{Au}(\mathrm{I})$-acetylide complex 8 even at $-25{ }^{\circ} \mathrm{C}$ to give alkyne homocoupling product 18 (ref. 24) and $\mathrm{Ph}_{3} \mathrm{PAuCl}$. As in the previous case, only one $\mathrm{Cl} /$ alkyne ligand exchange took place (Fig. S28 and S29 in the ESI†). Also in contrast to 13 , cis- $\mathrm{Ph}_{3} \mathrm{PAu}\left(\mathrm{C} \equiv \mathrm{C}-\mathrm{CO}_{2} \mathrm{Me}\right)(\mathrm{Cl})_{2}(\mathbf{1 0})$ proved to be completely unreactive towards electron-rich aromatic nucleophiles even after prolonged heating at $130{ }^{\circ} \mathrm{C}$ (Fig. S30 and S31 in the ESI $\dagger$ ). ${ }^{16 b, 25}$ The experiments summarized in Table 1 showcase the strong differences in reactivity for diacetato$\mathrm{Au}(\mathrm{III})$ vs. dichloro-Au(III) complexes ${ }^{26}$ and highlight the importance of the oxidant of choice, i.e. the ligand that ultimately the oxidant transfers onto the metal center, for a productive reaction outcome. In line with this hypothesis, replacement of the chloro ligands in $\mathbf{1 0}$ by reaction with 1 equivalent of LiOAc in the presence of 1,3,5-trimethoxybenzene in excess resulted in the clean formation of $\mathrm{Ph}_{3} \mathrm{PAuCl}$ and alkynylation product 19 in $61 \%$ yield (eqn (6)).

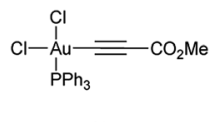

10

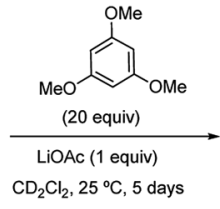

$\mathrm{CD}_{2} \mathrm{Cl}_{2}, 25^{\circ} \mathrm{C}, 5$ days

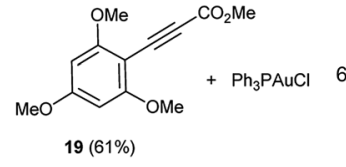

Additional stoichiometric experiments with $\mathrm{Au}(\mathrm{I})$-acetylide complex 8 were designed. When the reaction of 3,5-dimethoxytoluene (4) was run using $\mathrm{Au}(\mathrm{I})$-acetylide $\mathbf{8}$ as the stoichiometric alkynylating agent in the presence of $\mathrm{PhI}(\mathrm{OAc})_{2}$ and $\mathrm{NaHCO}_{3}$ only traces of the desired cross-coupling product 6 were detected (eqn (7), Fig. S32 and S33 in the ESI†). In contrast, when methyl propiolate (5) was incorporated into the reaction, arylalkyne product 6 was clearly observed after only one hour even if in low conversion (eqn (8), Fig. S34 and S35 in the ESI†). A catalytic version of this reaction using $5 \mathrm{~mol} \%$ of 8 or $\mathrm{Ph}_{3}$ PAuOAc also afforded 6 although again, in a much less efficient manner compared to the standard conditions (eqn (9), Fig. S36 and S37 in the ESI $\dagger$ ).
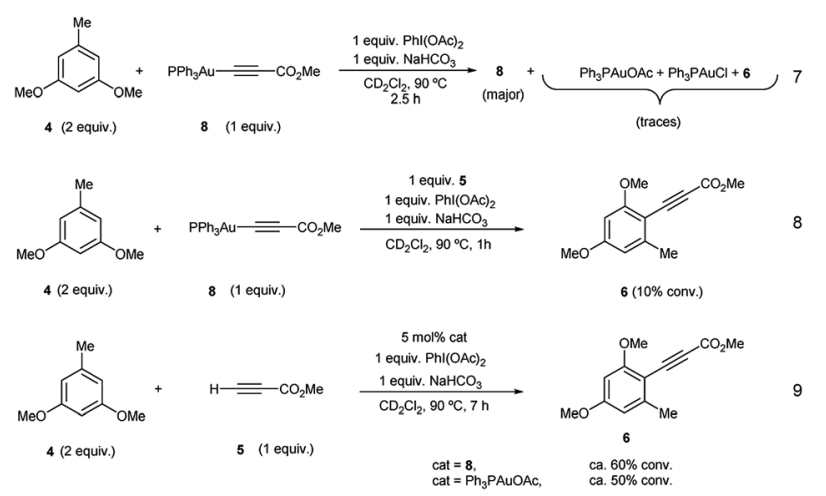

These experiments clearly suggest that the presence of free alkyne in the reaction mixture favors a productive reaction 
outcome and together with eqn (2) highlight that $\mathrm{PhI}(\mathrm{OAc})_{2}$ is not an efficient oxidant for 8 and the putative $\mathrm{Ph}_{3} \mathrm{PAu}\left(\mathrm{C} \equiv \mathrm{C}-\mathrm{CO}_{2} \mathrm{Me}\right)(\mathrm{OAc})_{2}$ (9) complex is not a highly competent reaction intermediate. Additionally, the reactions shown in Fig. $2 b-d$ indicated that the oxidant is involved in the activation of the alkyne. We hypothesized that the formation of $\mathbf{8}$ could occur by ligand exchange on $\mathrm{Ph}_{3} \mathrm{PAuCl}$ in the presence of $\mathrm{PhI}(\mathrm{OAc})_{2}$ to form $\mathrm{Ph}_{3} \mathrm{PAuOAc}$ which rapidly activates the alkyne $\mathbf{5}$ to form $\mathbf{8}$ and $\mathrm{AcOH}$, which is then quenched by $\mathrm{NaHCO}_{3}$ present in the reaction media (Fig. 2d). This proposal is supported by recent experiments of Shi et al., showing the formation of $\mathrm{R}_{3} \mathrm{PAuOAc}$ in the presence of $\mathrm{R}_{3} \mathrm{PAuCl}$ and $\mathrm{PhI}(\mathrm{OAc})_{2}$ by MALDI-MS analysis. ${ }^{27}$ Thus, to gain a deeper insight into the specific nature of the individual steps involved in these transformations, DFT calculations and additional control experiments were carried out.

\section{DFT studies and characterization of the oxidizing species}

In line with the experimental observations summarized in Fig. 2, calculations confirmed that formation of $\mathrm{Au}(\mathrm{I})$-acetylide 8 from $\mathrm{Ph}_{3} \mathrm{PAuCl}$ in the absence of oxidant is a highly unfavorable process even in the presence of base $\left(+19.1 \mathrm{kcal} \mathrm{mol}^{-1}\right.$, Fig. 3a). The lack of reactivity observed for $\mathrm{Ph}_{3} \mathrm{PAuCl}$ in the presence of $\mathrm{PhI}(\mathrm{OAc})_{2}$ could also be confirmed. A potential $\mathrm{Au}(\mathrm{Cl}) / \mathrm{I}(\mathrm{OAc})$ exchange is also disfavored $\left(+12.8 \mathrm{kcal} \mathrm{mol}^{-1}\right)$, and thus such an equilibrium would be strongly shifted towards the starting materials (Fig. $3 \mathrm{~b}$ ). When alkyne is added into the system, the energies of these two equilibria remain unchanged. However, the trace amounts of $\mathrm{Ph}_{3} \mathrm{PAuOAc}$ that could be produced rapidly react with the free alkyne present in the media to give $\mathrm{Au}(\mathrm{I})$ acetylide complexes and acetic acid, which will be quenched with the base present in the reaction (Fig. $3 \mathrm{c}$ and $2 \mathrm{~d}$ ). The energy for this process decreases to $+6.3 \mathrm{kcal} \mathrm{mol}^{-1}$. Thus, the second equilibria will drive the first one towards the right, influenced by the presence of free alkyne. Furthermore, the in situ generated $\mathrm{PhI}(\mathrm{OAc})(\mathrm{Cl})$ intermediate presents a much lower activation energy towards the oxidation of $\mathrm{Au}(\mathrm{I})$ acetylide via $\mathbf{T S}_{3}$ $\left(+20.1 \mathrm{kcal} \mathrm{mol}^{-1}\right)$ compared to $\mathrm{PhI}(\mathrm{OAc})_{2}$ via $\mathbf{T S}_{3}{ }^{\prime}(+29.2 \mathrm{kcal}$ $\left.\mathrm{mol}^{-1}\right)$ (Fig. 3d).

Stoichiometric experiments were subsequently designed to support the hypothesis of a $\mathrm{Au}(\mathrm{Cl}) / \mathrm{I}(\mathrm{OAc})$ ligand exchange triggered by the presence of free alkyne and the formation of a more reactive "non-symmetrical" oxidant. In an attempt to detect such species by highly sensitive ${ }^{19} \mathrm{~F}$ NMR spectroscopy, a fluorine-containing iodonium diacetate, namely $m$-F$\mathrm{C}_{6} \mathrm{H}_{4} \mathrm{I}(\mathrm{OAc})_{2}$ (20), was synthesized. ${ }^{28}$

The in situ kinetic studies of a reaction between 20, methyl propiolate (5) and $\mathrm{Ph}_{3} \mathrm{PAuCl}$ revealed the consumption of $\mathbf{2 0}$ and the simultaneous formation of a new product with a characteristic ${ }^{19} \mathrm{~F}$ signal at $107.5 \mathrm{ppm}$ which was assigned to $\mathrm{m}$-F$\mathrm{C}_{6} \mathrm{H}_{4} \mathrm{I}(\mathrm{OAc})(\mathrm{Cl})(21)$ (Fig. $4 \mathrm{a}$ and b). The oxidizing potential of 21 is higher than that of $\mathbf{2 0}$ as already revealed by the DFT calculations (Fig. 3d) and thus the $\mathrm{Au}(\mathrm{I})$-acetylide complex 8 which has been generated in situ can be slowly oxidized even at room temperature, thus preventing the accumulation of 21 in the reaction media. In the absence of other species, an OAc-alkyne ligand exchange reaction on the $\mathrm{Au}(\mathrm{III})$-acetylide intermediate
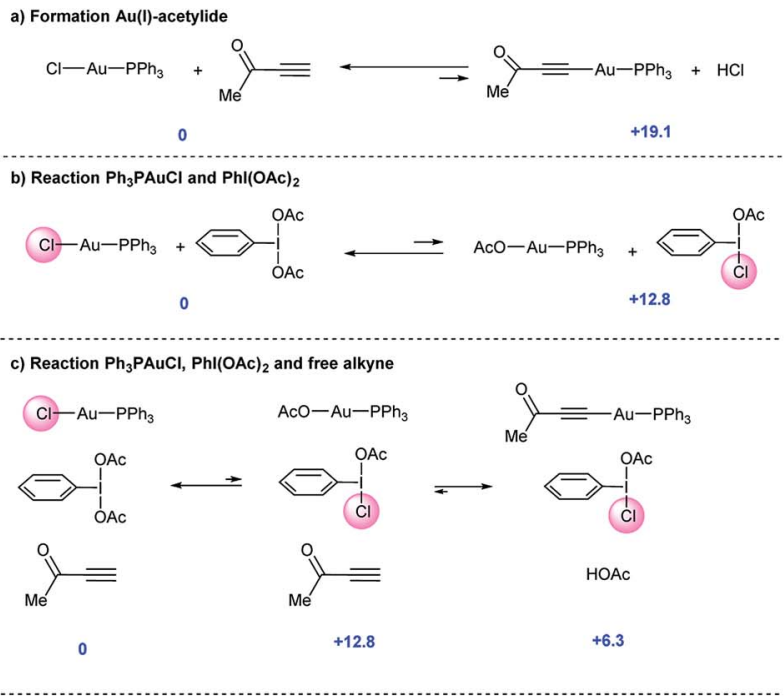

d) Oxidation of $\mathrm{Au}(\mathrm{l})$-acetylide by $\mathrm{Phl}(\mathrm{OAC})(\mathrm{Cl})\left(\mathrm{TS}_{3}\right)$ and $\mathrm{Phl}(\mathrm{OAC})_{2}\left(\mathrm{TS}_{3}\right)$
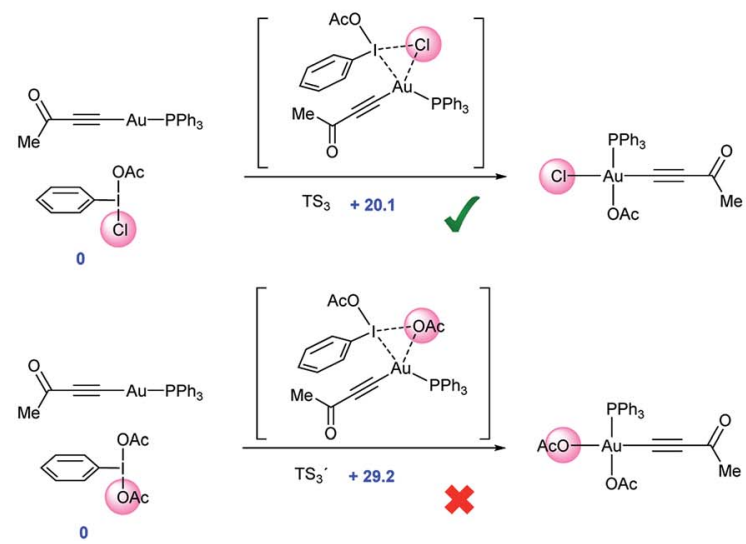

Fig. 3 (a-d) Computed Gibbs free energy values ( $\mathrm{kcal} \mathrm{mol}^{-1}$ ) for the potential reaction between $\mathrm{Ph}_{3} \mathrm{PAuCl}$, alkyne (methyl alkynyl ketone) and hypervalent iodine reagents calculated with the M06 functional.

(red path) or a transmetalation between the $\mathrm{Au}(\mathrm{I})$ and $\mathrm{Au}(\mathrm{III})$ acetylide species coexisting in the reaction media (blue path) could explain the formation of homocoupling product 18, which is produced in a comparable ratio to that in which 20 is consumed (Fig. 4c). Additional experiments were carried out to support the proposed structure of compound 21: the reaction of $m-\mathrm{F}-\mathrm{C}_{6} \mathrm{H}_{4} \mathrm{I}(\mathrm{Cl})_{2}$ with 1 equivalent of AgOAc delivered, after only 5 min, the same species observed in the ${ }^{19} \mathrm{~F}$ NMR spectrum, thus confirming the proposed composition of the "non-symmetric" oxidant (Fig. 4d) (for these and additional control experiments, see Section 3.8 in the ESI†).

To confirm the ability of chloride transfer from $\mathrm{Ph}_{3} \mathrm{PAuCl}$ to $\mathrm{PhI}(\mathrm{OAc})_{2}$, the standard cross-coupling reaction was performed in the presence of 1 equivalent of $(n-\mathrm{Bu})_{4} \mathrm{NCl}$ (see Section 3.9 in the ESI + ). As expected, the initial excess of chloride in the reaction mixture inhibited the formation of the desired crosscoupling product. In turn, 2-chloro-3,5-dimethoxytoluene could be detected, pointing towards in situ generated 21, which in this case is produced in abundant quantities in the reaction media, as the chlorinating agent. In line with these results, in the 

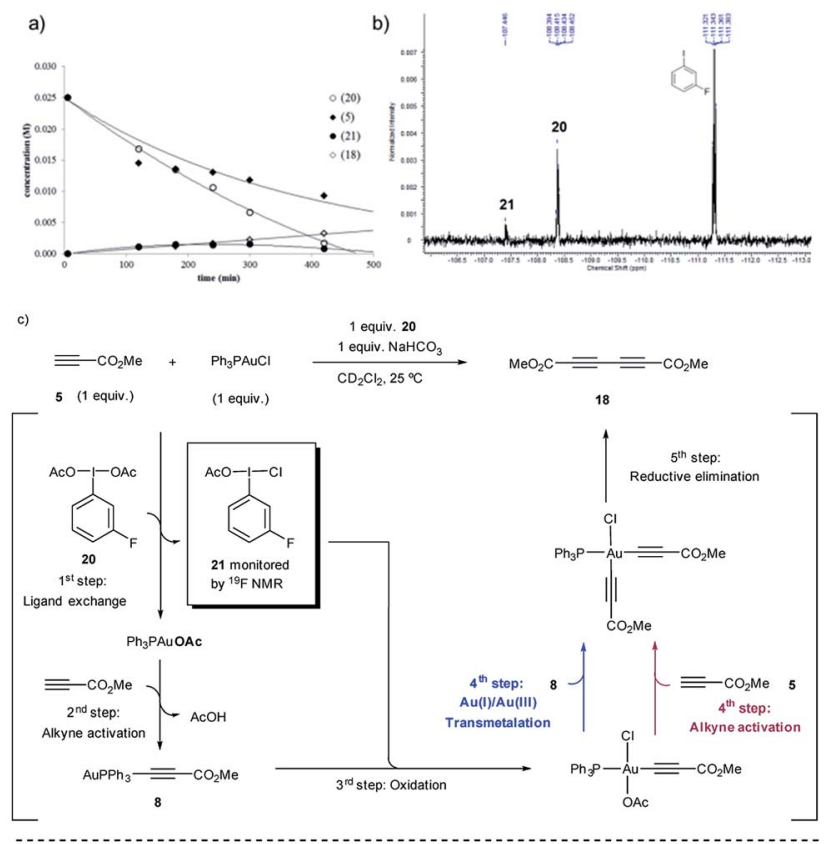

d)

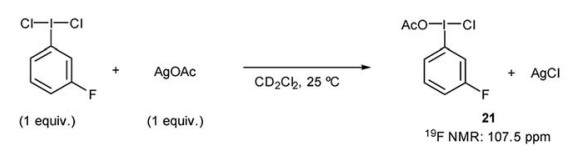

Fig. 4 Formation of "non-symmetric" I(III) species by reaction of $m-\mathrm{F}-\mathrm{C}_{6} \mathrm{H}_{4} \mathrm{I}(\mathrm{OAc})_{2} 20$ with $\mathrm{Ph}_{3} \mathrm{PAuCl}$ and methyl propiolate (5): (a) Evolution of the temporal concentration of reactants, intermediates and product. (b) ${ }^{19} \mathrm{~F}$ NMR traces of the reaction mixture. (c) Rationalization of the observed species. (d) Alternative synthesis and characterization of $m-\mathrm{F}-\mathrm{C}_{6} \mathrm{H}_{4} \mathrm{I}(\mathrm{OAc})(\mathrm{Cl})(21)$.

absence of chloride available for ligand exchange, the performance of 8 or $\mathrm{Ph}_{3} \mathrm{PAuOAc}$ as catalysts (eqn (9)) delivered the cross-coupling product in lower yield compared to the standard conditions.

Finally, DFT calculations were carried out to map the entire energy potential surface (Fig. 5). The mixture of free alkyne, $\mathrm{PhI}(\mathrm{OAc})_{2}$ and $\mathrm{Ph}_{3} \mathrm{PAuCl}$ was taken as the ground state of energy ( $G=0 \mathrm{kcal} \mathrm{mol}^{-1}$ ), mimicking the initial experimental conditions. As detailed in Fig. 5, the $\mathrm{Cl} / \mathrm{OAc}$ anion exchange between the gold and the iodine center through $\mathbf{T S}_{\mathbf{1}}$ (with $\mathrm{Au}-\mathrm{O}_{1}$ and $\mathrm{I}-\mathrm{Cl}$ bond distances of 2.35 and $2.90 \AA$ respectively) leads to a first high energy mixture, $\mathbf{I N T}_{\mathbf{1}}\left(+12.8 \mathrm{kcal} \mathrm{mol}^{-1}\right)$, which is readily transformed into $\mathbf{I N T}_{\mathbf{2}}\left(+6.3 \mathrm{kcal} \mathrm{mol}^{-1}\right)$ by deprotonation of the alkyne, alkynyl-gold complex formation and HOAc release via TS $_{2}$ (with bond distances: $\mathrm{Au}-\mathrm{C}_{1}=2.34 \AA$, $\mathrm{Au}-\mathrm{O}_{1}=2.46 \AA$ and $\left.\mathrm{C}_{1}-\mathrm{H}=1.23 \AA\right) .{ }^{29}$ The oxidation of the alkynyl-gold complex by the active oxidant species $\mathrm{PhI}(\mathrm{OAc})(\mathrm{Cl})$ presents an affordable activation energy ( $+20.1 \mathrm{kcal} \mathrm{mol}^{-1}$ from $\mathbf{I N T}_{\mathbf{2}}$ to $\left.\mathbf{T S}_{3}\right)$, involving the rupture of the $\mathrm{I}-\mathrm{Cl}$ bond $(\mathrm{I}-\mathrm{Cl}=3.10 \AA$, $\mathrm{Au}-\mathrm{Cl}=2.67 \AA$, $\mathrm{Au}-\mathrm{I}$ $=3.32 \AA$ and $\mathrm{Au}-\mathrm{C}_{1}=2.0 \AA$ ). The alternative $\mathrm{Au}(\mathrm{I})$ to $\mathrm{Au}(\mathrm{III})$ oxidation involving the I-OAc bond of $\mathrm{PhI}(\mathrm{OAc})(\mathrm{Cl})$ is disfavoured by more than $8 \mathrm{kcal} \mathrm{mol}^{-1}$ with respect to $\mathbf{T S}_{\mathbf{3}}$ (Fig. 3d). After the oxidation via $\mathbf{I N T}_{3}$, iodobenzene is released to form a highly stable neutral intermediate $\mathbf{I N T}_{\mathbf{5 A}}\left(-17.9 \mathrm{kcal} \mathrm{mol}^{-1}\right)$.
The arene reacts then with $\mathbf{I N T}_{\mathbf{5 A}}$ and the acetate ligand abstracts the proton to restore the aromaticity via $\mathbf{T S}_{\mathbf{4 A}}$ in an overall highly exergonic process to give $\mathbf{I N T}_{\mathbf{6}}\left(-29.7 \mathrm{kcal} \mathrm{mol}^{-1}\right.$ from $\mathbf{I N T}_{3}$ ), which is followed by a fast reductive elimination (the energy profile calculated for a dissociative interaction of the arene with $\mathbf{I N T}_{3}$ can be found in Fig. S69 in the ESI $\dagger$ ). ${ }^{\mathbf{1 5}}$ Deuterium labelling experiments on the arene carried out in our seminal study ${ }^{7}$ showed no primary KIE, in line with the present DFT results in which arene auration is not turnover limiting. $\mathrm{Ph}_{3} \mathrm{PAuCl}$ is formed in the final stage, re-entering the cycle, which shows an overall reaction energy of $-81 \mathrm{kcal} \mathrm{mol}^{-1}$. Thus, the DFT calculations support the hypothesis of the transformation of gold(I)-chloride into gold(I)-acetate (INT $\mathbf{1}$ ), and this into $\mathrm{Au}(\mathrm{I})$-acetylide ( $\mathbf{I N T}_{2}$ ) through two up-hill equilibria. The activation energies for these processes are comparable to that of the subsequent oxidation step by the in situ generated $\mathrm{PhI}(\mathrm{OAc})(\mathrm{Cl})$ via transition state $\mathbf{T S}_{\mathbf{3}}$ and also to that of the attack of the arene onto the alkynyl-gold(III) intermediate via $\mathbf{T S}_{\mathbf{4 A}}$. DFT calculations also confirmed the lability of the arylaurate intermediate ( $\mathbf{I N T}_{\mathbf{6}}$ ), which rapidly evolves via reductive elimination towards the cross-coupling product regenerating the $\mathrm{Ph}_{3} \mathrm{PAuCl}$ catalyst. ${ }^{23,30}$

\section{Proposed catalytic cycle}

The data presented in previous sections enabled a more detailed mechanism for the Au-catalyzed alkynylation of arenes to be proposed based on a better understanding of both oxidant and catalyst speciation for a productive reaction outcome (Scheme 3).

At the outset of the reaction, the formation of an $\mathrm{Au}(\mathrm{I})$-acetylide complex $\mathbf{F}$ takes place. However, the reaction of methyl propiolate (E) and $\mathrm{Ph}_{3} \mathrm{PAuCl}$ in the presence of a base to give acetylide complex $\mathbf{F}$ is not a favorable process (Fig. 2b). In contrast, the same reaction in the presence of $\mathrm{PhI}(\mathrm{OAc})_{2}$ revealed the formation of $\mathbf{F}$ after only 5 minutes (Fig. 2c), in line with the spectroscopic analysis of a catalytic reaction (Fig. 2a). These results led us to discard a facile equilibrium between the Au pre-catalyst and the alkyne while suggesting a new role for the oxidant in the initial steps of this transformation. Studies, including F-labeling experiments and DFT calculations, support a mechanistic scenario involving multiple equilibria between the alkyne, oxidant and gold. Initially, a ligand exchange between $\mathrm{Ph}_{3} \mathrm{PAuCl}$ and $\mathrm{PhI}(\mathrm{OAc})_{2}$ delivers $\mathrm{Ph}_{3}$ PAuOAc and a non-symmetric oxidant, $\mathrm{PhI}(\mathrm{OAc})(\mathrm{Cl})$. As shown in Fig. 2d, 3a and $b$, free alkyne reacts with the trace amounts of $\mathrm{Ph}_{3} \mathrm{PAuOAc}$ to give $\mathrm{Au}(\mathrm{I})$-acetylide complex $\mathbf{F}$ and acetic acid, which is quenched in the presence of $\mathrm{NaHCO}_{3}$. Experimentally, the formation of a non-symmetric hypervalent iodine $m$-F-PhI $(\mathrm{OAc})(\mathrm{Cl})$ (21) could also be monitored by ${ }^{19} \mathrm{~F}$ NMR (Fig. 4). This new oxidant formed in situ presents a lower activation energy towards the oxidation of $\mathbf{F}$ into $\mathrm{Au}(\mathrm{III})$-acetylide complex G compared to $\operatorname{PhI}(\mathrm{OAc})_{2}\left(\Delta \Delta G^{\dagger}\right.$ ca. $9 \mathrm{kcal} \mathrm{mol}^{-1}$, Fig. 3d). Experiments summarized in eqn (2) and (7)-(9) clearly suggest that free alkyne favors a productive reaction outcome and also that $\mathrm{PhI}(\mathrm{OAc})_{2}$ is not an efficient oxidant for 8 nor is the putative $\mathrm{Ph}_{3} \mathrm{PAu}\left(\mathrm{C} \equiv \mathrm{C}-\mathrm{CO}_{2} \mathrm{Me}\right)(\mathrm{OAc})_{2}$ (9) complex a highly competent reaction intermediate. Still, alternative reaction 


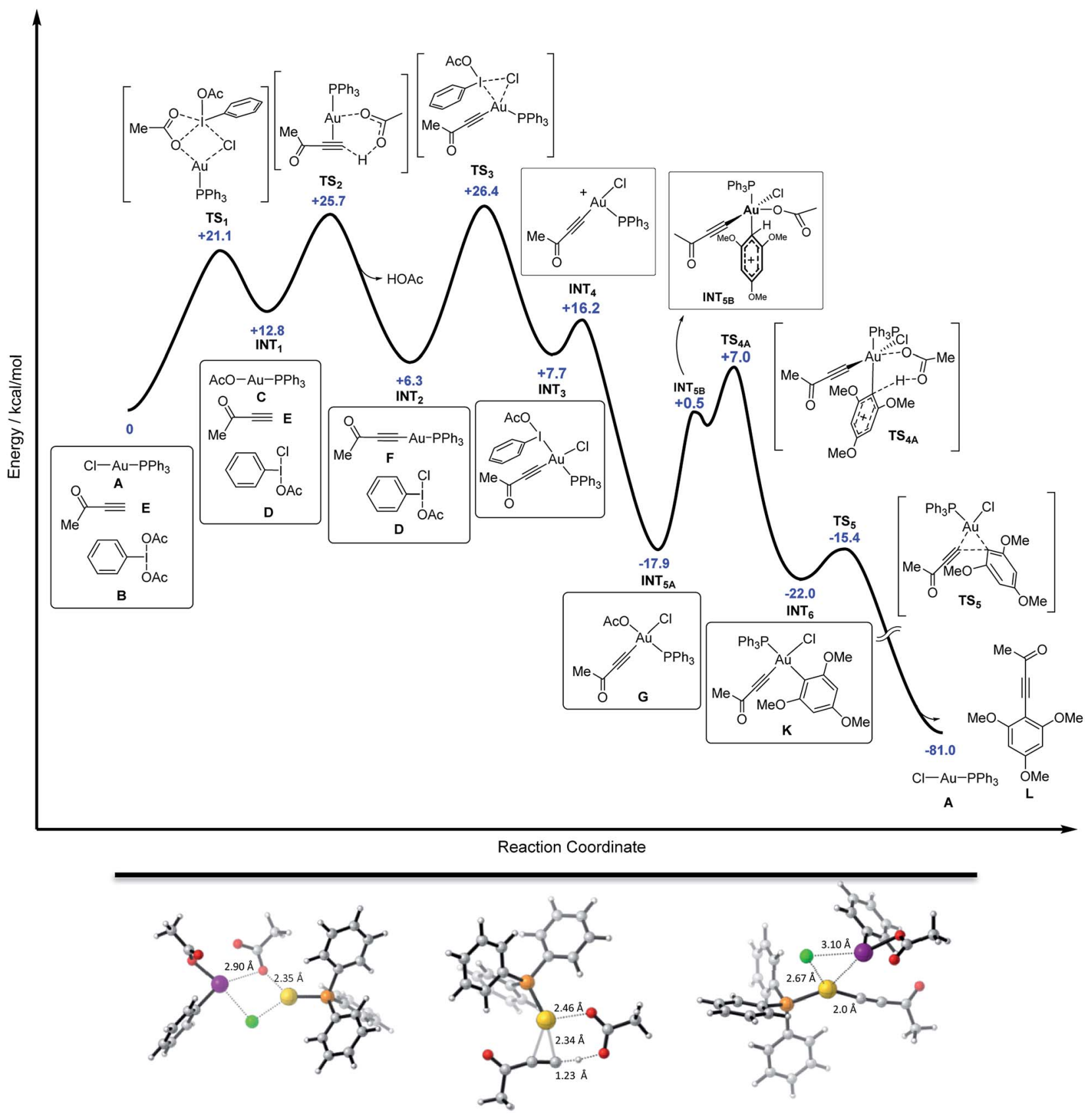

Fig. 5 Top: complete energy profile for the reaction between $\mathrm{Ph}_{3} \mathrm{PAuCl}$, alkyne (methyl alkynyl ketone), Phl(OAc) 2 and arene $(1,3,5$-trimethoxybenzene). Gibbs free energy values in blue calculated with the M06 functional. Bottom: structures of transition states $\mathrm{TS}_{1}, \mathrm{TS}_{2}$ and $\mathrm{TS}_{3}$ (left to right) highlighting the relevant distances.

pathways operating with $\mathrm{PhI}(\mathrm{OAc})_{2}$ as the oxidant cannot be completely ruled out (eqn (9)). Putative analogues of Au(III) complexes $\mathbf{G}$ (10 and $\mathbf{1 3}$ in Table 1) were used as mechanistic probes in stoichiometric experiments which revealed the crucial role of anionic ligands in the reaction outcome. Thus, acetato ligands on the $\mathrm{Au}$ (III) center can be rapidly exchanged in the presence of arenes whereas the corresponding chlorides remain unreacted.

A competitive OAc/alkyne exchange in $\mathbf{G}$ to give $\mathbf{G}^{\prime}$ can occur although in a sufficiently slower rate to enable a productive cross coupling reaction rather than the undesired homocoupling of alkyne, which is sometimes observed as a minor byproduct in these transformations. Although a $\mathrm{Au}(\mathrm{I}) / \mathrm{Au}(\mathrm{III})$ transmetalation involving the chloride ligands towards the formation of a bis-alkynyl $\mathrm{Au}(\mathrm{III})$ intermediate cannot be completely ruled out, ${ }^{\mathbf{1 8 , 3 1}}$ control experiments indicate that this process might be slow under the present reaction conditions (see Fig. 4c and S51-S57 in the ESI $\dagger$ ).

The proposed $\mathrm{Au}(\mathrm{Cl})-\mathrm{I}(\mathrm{OAc})$ exchange in the first steps of the reaction produces a "non-symmetric" $\operatorname{ArI}(\mathrm{Cl})(\mathrm{OAc})$ oxidant 


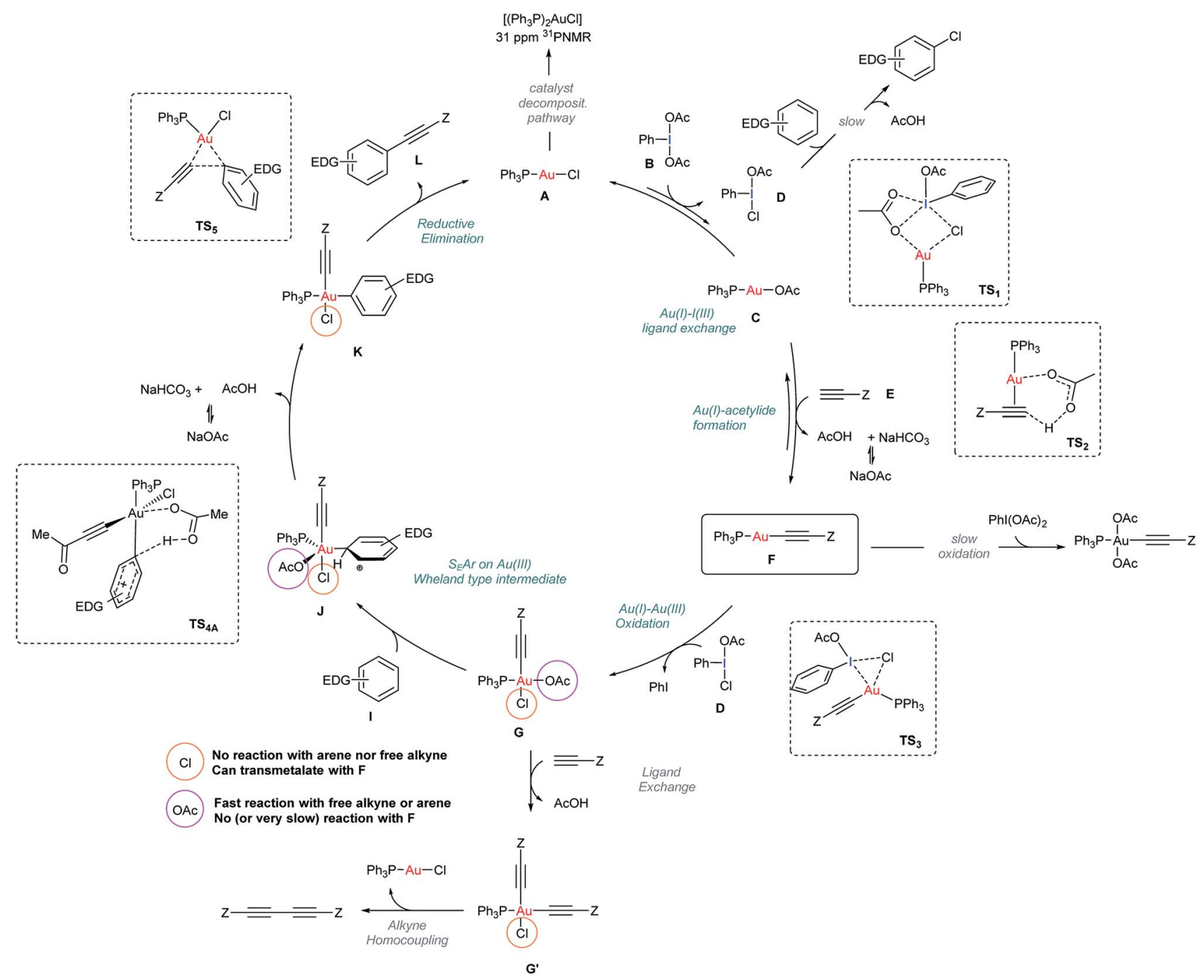

Scheme 3 Mechanistic proposal for the Au-catalyzed alkynylation of arenes. Structures of $\mathrm{TS}_{1}, \mathrm{TS}_{2}, \mathrm{TS}_{3}$ and $\mathrm{TS}_{5}$ stem from DFT calculations reported in Fig. 5.

responsible for reaction by-products stemming from the direct oxidation (i.e. chlorination) of the arene $(<5 \%)$ (Section 4.2 in the ESI $\dagger) .{ }^{32}$ Finally, the mechanism for catalyst decomposition has also been studied. Slow de-coordination of $\mathrm{Ph}_{3} \mathrm{P}$ from the neutral starting complex $\mathrm{Ph}_{3} \mathrm{PAuCl}$ or other phosphine-Au species involved in the reaction results in the formation of trace amounts of $\left(\mathrm{Ph}_{3} \mathrm{P}\right)_{2} \mathrm{AuX}(7)$ visible in the ${ }^{31} \mathrm{P}$ NMR of the standard catalytic reaction media (Fig. 2a). Control experiments revealed that these species are catalytically inactive and do not interfere with a productive reaction outcome (see Section 4.3 in the ESI $\dagger)^{33}$

\section{Conclusions}

A detailed investigation of the gold-catalyzed alkynylation of arenes including kinetic and stoichiometric experiments together with DFT calculations has provided an insightful perspective on the mechanism of this transformation. A ligand exchange involving the alkyne, $\mathrm{Au}(\mathrm{I})$-catalyst and oxidant is needed to form both a $\mathrm{Au}(\mathrm{I})$-acetylide complex and a more reactive "non-symmetric" oxidant $\mathrm{PhI}(\mathrm{OAc})(\mathrm{Cl})$ responsible for the crucial $\mathrm{Au}(\mathrm{I}) / \mathrm{Au}(\mathrm{III})$ turnover. Both processes, i.e. the formation of $\mathrm{Au}(\mathrm{I})$-acetylide and its oxidation, are connected through an equilibrium which evolves along the reaction progress. Reaction of the electron rich arenes with the in situ generated $\mathrm{Au}$ (III)-alkynyl intermediate occurs to produce a shortlived aryl-alkynyl-Au(III) complex, which evolves by reductive elimination to produce the observed cross-coupling products and the $\mathrm{Au}(\mathrm{I})$ catalyst. The mechanisms of both catalyst decomposition and competing side reactions have also been unraveled.

A few of the lessons learned in this study may also be applicable to other gold-catalyzed oxidative cross-couplings employing I(III) oxidants. Unexpectedly, a ligand exchange between the gold(I) pre-catalyst and the initial hypervalent iodine might be the key to produce the suitable gold(I)-species to enable activation of the alkyne in the first place. Furthermore, the same process provides the appropriate oxidizing species, 
capable of producing reactive $\mathrm{Au}(\mathrm{III})$-intermediates. This process is influenced by both the nature of the ancillary ligand on gold and by the presence of other reaction partners which can shift this uphill equilibria. Oxidation is also an energetically demanding process which translates into a $\mathrm{Au}(\mathrm{III})$-intermediate, whose reactivity will be fine-tuned by the nature of the anionic ligands transferred by the oxidant: while acetato ligands favor activation of the arene and are easily displaced to give the cross-coupling products, chlorides are much less reactive and thus stabilize these species favoring transmetalation processes. We believe that this mechanistic study supporting $\mathrm{Au}(\mathrm{I}) / \mathrm{Au}(\mathrm{III})$ redox catalytic cycles provides novel insights, useful not only for the development of new gold catalyzed oxidative transformations but also for the improvement and fine tuning of already available ones.

\section{Conflicts of interest}

There are no conflicts to declare.

\section{Acknowledgements}

We thank the European Research Council (ERC Starting grant agreement no. 307948) and the Swiss National Science Foundation (SNF 200020_146853) for financial support and the SGI/ IZO-SGIker UPV/EHU and Schrödinger (UZH) for allocation of computational resources. We thank Dr A. Linden for the X-ray crystal structure determination of 10 (CCDC-1008765). $\dagger$

\section{Notes and references}

1 (a) P. J. Garatt, in Comprehensive Organic Synthesis, ed. B. M. Trost and I. Fleming, Pergamon, Oxford, 1991, vol. 3, p. 271; (b) Acetylene Chemistry: Chemistry, Biology and Material Science, ed. F. Diederich, P. J. Stang and R. R. Tykwinski, Wiley-VCH, Weinheim, 2005.

2 (a) Metal-Catalyzed Cross-Coupling Reactions, ed. A. de Meijere and F. Diederich, Wiley-VCH, Weinheim, 2nd edn, 2004, vol. 1, p. 2; (b) R. Chinchilla and C. Najera, Chem. Rev., 2007, 107, 874-922.

3 For recent reviews in $\mathrm{C}-\mathrm{H}$ arylation, see: (a) Modern Arylation Methods, ed. L. Ackermann, Wiley-VCH, Weinheim, Germany, 2009, p. 311; (b) R. Giri, B.-F. Shi, K.-M. Engle, N. Maugel and J.-Q. Yu, Chem. Soc. Rev., 2009, 38, 32423272; (c) O. Daugulis, H.-Q. Do and D. Shabashov, Acc. Chem. Res., 2009, 42, 1074; (d) J. Roger, A. L. Gottumukkala and H. Doucet, ChemCatChem, 2010, 2, 20-40.

4 (a) F. Besselievre and S. Piguel, Angew. Chem., Int. Ed., 2009, 48, 9553-9556; (b) Z. Shao and F. Peng, Angew. Chem., Int. Ed., 2010, 49, 9566-9568; (c) A. S. Dudnik and V. Gevorgyan, Angew. Chem., Int. Ed., 2010, 49, 2096-2098; (d) N. Matsuyama, M. Kitahara, K. Hirano, T. Satoh and M. Miura, Org. Lett., 2010, 12, 2358-2361; (e) B. Pacheco Berciano, S. Lebrequier, F. Besselievre and S. Piguel, Org. Lett., 2010, 12, 4038-4041; (f) C. Theunissen and G. Evano, Org. Lett., 2014, 16, 4488-4491.

5 Y. Wei, H. Zhao, J. Kan, W. Su and M. Hong, J. Am. Chem. Soc., 2010, 132, 2522-2523.
6 (a) J. P. Brand, J. Charpentier and J. Waser, Angew. Chem., Int. Ed., 2009, 48, 9346-9349; (b) J. P. Brand and J. Waser, Angew. Chem., Int. Ed., 2010, 49, 7304-7307; (c) J. P. Brand, C. Chevalley and J. Waser, Beilstein J. Org. Chem., 2011, 7, 565-569; (d) J. P. Brand, C. Chevalley, R. Scopelliti and J. Waser, Chem.-Eur. J., 2012, 18, 5655-5666; (e) Y. Li, J. P. Brand and J. Waser, Angew. Chem., Int. Ed., 2013, 52, 6743-6747; (f) Y. Li and J. Waser, Beilstein J. Org. Chem., 2013, 9, 1763; $(g)$ J. P. Brand, Y. Li and J. Waser, Isr. J. Chem., 2013, 53, 901-910.

7 T. de Haro and C. Nevado, J. Am. Chem. Soc., 2010, 132, 15121513.

8 For a Au-catalyzed tandem allenoate cyclization/alkynylation protocol with Selectfluor as the oxidant, see: M. N. Hopkinson, J. E. Ross, G. T. Giuffredi, A. D. Gee and V. Governeur, Org. Lett., 2010, 12, 4904-4907.

9 Y. Fuchita, Y. Utsonomiya and M. Yasutake, J. Chem. Soc., Dalton Trans., 2001, 2330-2334.

10 (a) V. V. Zhdankin, ARKIVOC, 2009, 1; (b) R. M. Moriarty, Org. Chem., 2005, 70, 2893-2903; (c) J. P. Brand, D. Fernandez Gonzalez, S. Nicolai and J. Waser, Chem. Commun., 2011, 47, 102-115. For a seminal example of $\mathrm{Au}(\mathrm{I}) / \mathrm{Au}(\mathrm{III})$ involving hypervalent iodine reagents, see: A. Kar, N. Mangu, H. M. Kaiser, M. Beller and M. K. Tse, Chem. Commun., 2008, 386-388.

11 (a) N. R. Deprez and M. Sanford, Inorg. Chem., 2007, 46, 1924-1935; (b) P. A. Sibbald and F. E. Michael, Org. Lett., 2009, 11, 1147-1149; (c) T. Furuya, D. Benitez, E. Tkatchouk, A. E. Strom, P. Tang, W. A. Goddard III and T. Ritter, J. Am. Chem. Soc., 2010, 132, 3793-3801; (d) P. Sehnal, R. J. K. Taylor and I. J. S. Fairlamb, Chem. Rev., 2010, 110, 824-889.

12 (a) M. S. Kharasch and H. S. Isbell, J. Am. Chem. Soc., 1931, 53, 3053-3059; (b) K. S. Liddle and C. Parkin, J. Chem. Soc., Chem. Commun., 1972, 26; (c) P. W. J. deGraaf, J. Boersma and G. J. M. Van der Kerk, J. Organomet. Chem., 1976, 105, 399-406; (d) K. A. Porter, A. Schier and H. Schmidbaur, Organometallics, 2003, 22, 4922-4927.

13 For seminal contributions on $\mathrm{Au}(\mathrm{I}) / \mathrm{Au}(\mathrm{III})$ manifolds, see: (a) A. S. K. Hashmi, T. D. Ramamurthi and F. Rominger, $J$. Organomet. Chem., 2009, 694, 592-597; (b) L. Cui, G. Zhang and L. Zhang, Bioorg. Med. Chem. Lett., 2009, 19, 38843887; (c) G. Zhang, Y. Peng, L. Cui and L. Zhang, Angew. Chem., Int. Ed., 2009, 48, 3112-3115; (d) A. Iglesias and K. Muñiz, Chem.-Eur. J., 2009, 15, 10563-10569; (e) M. N. Hopkinson, A. Tessier, A. Salisbury, G. T. Giufredi, L. E. Combettes, A. D. Gee and V. Gouverneur, Chem.-Eur. J., 2010, 16, 4739-4744; (f) G. Zhang, L. Cui, Y. Wang and L. Zhang, J. Am. Chem. Soc., 2010, 132, 1474-1475; (g) W. E. Brenzovich, J.-F. Brazeau and F. D. Toste, Org. Lett., 2010, 12, 4728-4731; (h) L. T. Ball, M. Green, G. C. LloydJones and C. A. Russell, Org. Lett., 2010, 12, 4724-4727; (i) A. D. Melhado, W. E. Brenzovich, A. D. Lackner and F. D. Toste, J. Am. Chem. Soc., 2010, 132, 8885-8887; (j) T. de Haro and C. Nevado, Angew. Chem., Int. Ed., 2011, 50, 906-910; (k) L. T. Ball, G. C. Lloyd-Jones and C. A. Russell, Science, 2012, 337, 1644-1648; (l) C. X. Cambeiro, 
N. Ahlsten and I. Larrosa, J. Am. Chem. Soc., 2015, 137, 15636-15639. For selected reviews on this specific topic see: $(m)$ P. Garcia, M. Malacria, C. Aubert, V. Gandon and L. Fensterbank, ChemCatChem, 2010, 2, 493-497; (n) H. A. Wegner and M. Auzias, Angew. Chem., Int. Ed., 2011, 50, 8236-8247; (o) M. Hopkinson, A. D. Gee and V. Governeur, Chem.-Eur. J., 2011, 17, 8248-8262; (p) T. C. Boorman and I. Larrosa, Chem. Soc. Rev., 2011, 40, 1910-1925; (q) T. de Haro and C. Nevado, Synthesis, 2011, 16, 2530-2539; (r) C. Nevado and T. de Haro, in New Strategies in Chemical Synthesis and Catalysis, ed. B. Pignataro, Wiley-VCH, Weinheim, 2012, p. 247.

14 (a) E. Tkatchouck, N. P. Mankad, D. Benitez, W. A. Goddard III and F. D. Toste, J. Am. Chem. Soc., 2011, 133, 1429314300; (b) W. E. Brenzovich, D. Benitez, A. D. Lackner, H. P. Shunatona, E. Tkatchouk, W. A. Goddard III and F. D. Toste, Angew. Chem., Int. Ed., 2010, 49, 5519-5922; (c) L. T. Ball, G. C. Lloyd-Jones and C. A. Russell, J. Am. Chem. Soc., 2014, 136, 254-264; (d) J. Guenther, S. Mallet-Ladeira, L. Estevez, K. Miqueu, A. Amgoune and D. Bourissou, $J$. Am. Chem. Soc., 2014, 136, 1778-1781; (e) M. Joost, A. Zeineddine, L. Estevez, S. Mallet-Ladeira, K. Miqueu, A. Amgoune and D. Bourissou, J. Am. Chem. Soc., 2014, 136, 14654-14657; (f) D. A. Rosca, J. A. Wright, D. L. Hughes and M. Bochmann, Nat. Commun., 2013, 4, 2167-2175; ( $g$ ) D. A. Rosca, J. Fernández-Cestau, J. Morris, J. A. Wright and M. Bochmann, Sci. Adv., 2015, 1, e1500761; (h) T. J. A. Corrie, L. T. Ball, C. A. Russell and G. C. Lloyd-Jones, J. Am. Chem. Soc., 2017, 139, 245-254.

15 Additional control experiments, experimental procedures, and full characterization of new compounds can be found in the accompanying ESI. $\dagger$

16 (a) M. Hofer and C. Nevado, Eur. J. Inorg. Chem., 2012, 9, 1338-1341; (b) M. Hofer and C. Nevado, Tetrahedron, 2013, 69, 5751-5757.

17 (a) A. S. K. Hashmi, I. Braun, M. Rudolph and F. Rominger, Organometallics, 2012, 31, 644-661; (b) L. Ye, Y. Wang, D. H. Aue and L. Zhang, J. Am. Chem. Soc., 2012, 134, 3134; (c) A. Simmoneau, F. Jaroschik, D. Lesage, M. Karanik, R. Guillot, M. Malacria, J.-C. Tabet, J.-P. Goddard, L. Fensterbank, V. Gandon and Y. Gimbert, Chem. Sci., 2011, 2, 2417-2422; (d) A. S. K. Hashmi, I. Braun, P. Nösel, J. Schädlich, M. Wieteck, M. Rudolf and F. Rominger, Angew. Chem., Int. Ed., 2012, 51, 4456-4469; (e) M. M. Hansmann, M. Rudolf, F. Rominger and A. S. K. Hashmi, Angew. Chem., Int. Ed., 2012, 52, 2593-2598.

18 For a Au-catalyzed oxidative homocoupling of alkynes using Selectfluor, see: A. Leyva-Pérez, A. Doménech, S. I. Al-Resayes and A. Corma, ACS Catal., 2012, 2, 121-126. The authors propose the transmetalation between two alkynyl-Au species in different oxidation states $(\mathrm{Au}(\mathrm{I}) / \mathrm{Au}(\mathrm{III}))$ as the key step for the formation of the new Csp-Csp bond.

19 For an Au-catalyzed heterocoupling of alkynes, see: H. Peng, Y. Xi, N. Ronaghi, B. Dong, N. G. Akhmedov and X. Shi, J. Am. Chem. Soc., 2014, 136, 13174-13177. The gold activation of the triple bond on an alkynyl-Au(III) intermediate is proposed as the key step for this transformation. Control experiments in our system ruled out the $\pi$-activation of complex 8 under the standard reaction conditions.

$20 \mathrm{Ph}_{3} \mathrm{PAuCl}$, which is observed in minimal quantities, is produced by the slow activation of the chlorinated solvent as demonstrated by additional control experiments (see Fig. S16-S19 in the ESI $\dagger$ ).

21 B. B. Snider, D. M. Roush, D. J. Rodini, D. Gonzalez and D. Spindell, J. Org. Chem., 1980, 45, 2773-2785.

22 M. Hofer, A. Genoux, R. Kumar and C. Nevado, Angew. Chem., Int. Ed., 2017, 56, 1021.

23 W. J. Wolf, M. S. Winston and F. D. Toste, Nat. Chem., 2014, 6, 159-164.

24 The homocoupling production of methyl propiolate 18 presents a characteristic signal at $3.81 \mathrm{ppm}$ in the ${ }^{1} \mathrm{H}$ NMR: J. A. Varela, L. Castedo, M. Maestro, J. Mahía and C. Saá, Chem.-Eur. J., 2001, 7, 5203-5213.

25 The reactivity observed for complex $\mathbf{1 0}$ could also be reproduced with its pentafluorophenyl analogue $\mathrm{Ph}_{3} \mathrm{PAu}\left(\mathrm{C}_{6} \mathrm{~F}_{5}\right)(\mathrm{Cl})_{2}$. See ref. 16.

26 (a) A. Maleckis, J. W. Kampf and M. S. Sanford, J. Am. Chem. Soc., 2013, 135, 6618-6621; (b) K. J. Stowers and M. S. Sanford, Org. Lett., 2009, 11, 4584-4587; (c) D.-A. Rosca, D. A. Smith and M. Bochmann, Chem. Commun., 2012, 48, 7247-7249.

27 D.-H. Zhang, L.-Z. Dai and M. Shi, Eur. J. Org. Chem., 2010, 28, 5454-5459.

28 J. G. Sharefkin and H. Saltzman, Org. Synth., 1963, 43, 62.

$29 \mathrm{AcOH}$ reacts with the $\mathrm{NaHCO}_{3}$ present in the reaction media to form NaOAc thus bringing the effective energy of $\mathbf{I N T}_{\mathbf{2}}$ to an even lower level.

30 (a) J. Vicente, M. D. Bermudez, J. Escribano, M. P. Carrillo and P. G. Jones, J. Chem. Soc., Dalton Trans., 1990, 30833089; (b) J. Vicente, M. D. Bermudez and J. Escribano, Organometallics, 1991, 10, 3380-3384; (c) T. Lauterbach, M. Livendahl, A. Rosellon, P. Espinet and A. M. Echavarren, Org. Lett., 2010, 12, 3006-3009; (d) M. Hofer, E. Gomez-Bengoa and C. Nevado, Organometallics, 2014, 33, 1328-1332.

31 O. Schuster and H. Schmidbaur, Organometallics, 2005, 24, 2289-2296.

32 Products of propiolate polymerization, which have been observed in the presence of gold nanoparticles (A. LeyvaPerez, J. Oliver-Meseguer, J. R. Cabrero-Antonino, P. S. Rubio-Marques, S. I. Al-Resayes and A. Corma, ACS Catal., 2013, 3, 1865-1873) were not detected in the reaction mixtures.

33 (a) T. J. Harrison, J. A. Kozak, M. Corbella-Pané and G. R. Dake, J. Org. Chem., 2006, 71, 4525-4529; (b) G. H. Woehrle, L. O. Brown and J. E. Hutchison, J. Am. Chem. Soc., 2005, 127, 2172-2183; (c) A. Zhdanko, M. Ströbele and M. E. Maier, Chem.-Eur. J., 2012, 18, 14732-14744; (d) M. Kumar, J. Jasinski, G. B. Hammond and B. Xu, Chem.-Eur. J., 2014, 20, 3113-3119. 